\title{
MDM4 as a Prognostic Factor for Patients With Gastric Cancer With Low Expression of p53
}

\author{
XIAOCHEN ZHANG ${ }^{1}$, YOSHIYUKI YAMAMOTO ${ }^{1}$, XIAOXUAN WANG $^{1}$, \\ MASASHI SATO ${ }^{1}$, MAMIKO IMANISHI ${ }^{1}$, AKINORI SUGAYA ${ }^{2}$, MITSUAKI HIROSE ${ }^{1,3}$,

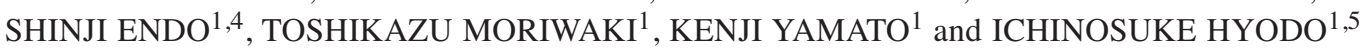 \\ ${ }^{1}$ Department of Gastroenterology, Institute of Clinical Medicine, \\ Graduate School of Comprehensive Human Sciences, University of Tsukuba, Tsukuba, Japan; \\ ${ }^{2}$ Division of Gastroenterology, Ibaraki Prefectural Central Hospital, Kasama, Japan; \\ ${ }^{3}$ Department of Gastroenterology, Tsuchiura Clinical Education and Training Center, \\ University of Tsukuba Hospital, Tsuchiura, Japan; \\ ${ }^{4}$ Department of Gastroenterology and Hepatology, Shinmatsudo Central General Hospital, Matsudo, Japan; \\ ${ }^{5}$ Department of Gastrointestinal Medical Oncology, NHO Shikoku Cancer Center, Matsuyama, Japan
}

\begin{abstract}
Background/Aim: The oncoproteins murine double minute (MDM) 2 and MDM4 inactivate tumor-suppressor protein 53. Their mutual relationship with the prognosis of gastric cancer $(G C)$ remains unknown. Patients and Methods: Expression of MDM2, MDM4, and p53 in tumors of 241 patients with GC were evaluated immunohistochemically. Effects of overexpression of MDM4 on tumor-growth properties and sensitivity to cytotoxic drugs were investigated using NUGC4 human GC cell line. Results: High expression of p53 was associated with poor overall survival in the whole population. Among 173 patients with low expression of p53 (implying nonmutation), high expression of MDM4 was an independent factor of poor prognosis in both stage I-III and IV, but of MDM2 was not. MDM4-transduced NUGC4 cells formed twice as many colonies and had a higher 50\% inhibitory concentration for 5-fluorouracil and oxaliplatin than did the control cells. Conclusion: MDM4 expression is a factor conferring poor prognosis in patients with GC with low expression of p53 and may confer drug resistance.
\end{abstract}

This article is freely accessible online.

Correspondence to: Yoshiyuki Yamamoto, Department of Gastroenterology, Institute of Clinical Medicine, University of Tsukuba, 1-1-1 Tennodai, Tsukuba, Ibaraki 305-8575, Japan. Tel: +81298533218, Fax: +81 298533218, e-mail: y-yamamoto@ md.tsukuba.ac.jp

Key Words: MDM2, MDM4, p53, gastric cancer, immunohistochemical study.
The gene TP53, which encodes the tumor-suppressor p53 protein in humans, is inactivated by mutations in various cancer types. The mutation rate of TP53 in gastric cancer (GC) is approximately $40 \%$ to $50 \%$ (1). In TP53 wild-type (WT) cancer, the gene function is often suppressed by enhanced expression of oncogenes such as murine double minute 2 (MDM2) and MDM4 (2-4).

In normal cells, cellular p53 is maintained at a very low level via regulation by MDM2 through an autoregulatory feedback loop (5-7). As a structural homolog of MDM2, MDM4 has gradually attracted attention in recent years. MDM4 not only inhibits p53 transcriptional ability by directly binding to the transactivation domain of p53 (8), but also promotes the ubiquitin-dependent degradation of $\mathrm{p} 53$ by forming a complex with MDM2 $(9,10)$.

In cancer cells, the complex and precise regulatory relationship among these three proteins is disrupted by mutations of TP53, and by overexpression of MDM2 and MDM4, leading to tumor growth. MDM2 overexpression is suggested to be a factor indicating a poor prognosis in patients with GC (11). According to the Human Protein Atlas (https://www.proteinatlas.org/ENSG00000198625MDM4), the prognostic value of MDM4 has been controversial for some types of cancer. In GC, the association between the expression levels of p53, MDM2, and MDM4 and cancer prognosis remains unknown. It is important to clarify the roles of MDM2 and MDM4 in patients with WT TP53 GC.

In this study, we investigated the regulatory relationship among these proteins using clinical data and tumor tissue samples. Moreover, we evaluated the effect of MDM4 overexpression on tumor-growth properties and sensitivity of cancer cells to cytotoxic drugs in an in vitro study. 


\section{Patients and Methods}

Patients. We retrospectively collected the clinical data and tumor tissue samples of patients with stage I-IV (12) GC who had undergone surgery or received chemotherapy at the University of Tsukuba Hospital between January 2006 and December 2018. This study was conducted according to Japanese ethical guidelines proposed by the Ministry of Education, Culture, Sports, Science and Technology and the Ministry of Health, Labor and Welfare (http://www.lifescience.mext.go.jp/files/pdf/n1443_01.pdf) and obtained the approval of the Ethics Review Committee (R01-197) of the University of Tsukuba Hospital. The requirement for informed consent was waived owing to the retrospective nature of the study.

Immunohistochemical staining. The expression of p53, MDM2, and MDM4 in the formalin-fixed paraffin-embedded tumor tissue samples were examined using immunohistochemistry (IHC) staining with anti-p53 (DO-7, ready-to-use; Dako, Glostrup, Denmark), antiMDM2 (2A10, diluted 1:80; Abcam, Cambridge, UK), anti-MDM4 (2D10F4, diluted 1:500; Thermo Fisher Scientific, Waltham, MA, USA) and EnVision+ System-HRP secondary antibody (K4001, ready-to-use; Dako). For the positive control for p53, MDM2, and MDM4, we used lung cancer, retinoblastoma, and colon cancer tissues, respectively. Negative controls were obtained by replacing the primary antibody with phosphate-buffered saline.

Based on previous reports $(13,14)$, we determined the expression status as follows: p53 was defined as high expression of when more than $25 \%$ of the tumor nuclei were obviously stained, and MDM2 and MDM4 were defined as high expression of when more than $50 \%$ of the tumor nuclei were stained (Figure 1). Expression status was independently judged by three investigators (X.Z., A.S., M.H.) blinded to the clinical data. Finally, we confirmed whether all of their judgments matched.

Study design. The primary endpoint was overall survival (OS), and secondary endpoints were disease-free (DFS) and progression-free (PFS) survival. OS was defined as the time from the date of curative resection in patients with stage I-III or the initiation of first-line chemotherapy to the date of death from any cause in those with stage IV. DFS was defined as the time from the date of curative resection to the date of recurrence or death. PFS was defined as the time from the date of initiation of firstline chemotherapy to the date of disease progression or death. Patients without OS events were censored at the date of the last follow-up. Patients without DFS or PFS events were censored at the date of the last tumor evaluation by use of computed tomographic scans.

Experiments using an MDM4-overexpressing cell line. Cell line and lentiviral transduction: NUGC4 human GC cell line with WT TP53 was obtained from the Riken BioResource Center Cell Bank (Tsukuba, Japan), and was cultured in RPMI 1640 medium (SigmaAldrich, St. Louis, MO, USA) supplemented with $10 \%$ fetal bovine serum (Nichirei Biosciences, Tokyo, Japan). MDM4 cDNA was isolated using the $3 \times$ FLAG-MdmX/pcDNA3.1 plasmid (a kind gift from Dr. M. Kitagawa) (15) and subcloned in a lentivirus expression plasmid (pLenti6.3/V5-DEST; Invitrogen, Carlsbad, CA, USA) according to the manufacturer's instructions. Enhanced green fluorescent protein (EGFP)- and MDM4-infectious recombinant viruses were produced using a ViraPower Bsd Lentiviral Support
Kit and 293FT cells (Invitrogen) and transduced in NUGC4 cells according to the manufacturer's instructions.

Immunoblot analysis: Immunoblot analysis was performed as described previously (16). To circumvent the low linear dynamic range of immunoblot analysis, serially diluted total protein extracts from MDM4-NUGC4 cells and undiluted extracts from EGFPNUGC4 cells were electrophoresed and probed for MDM4 levels. Mouse monoclonal antibody to MDM4 (D-4) and rabbit polyclonal antibody to $\beta$-actin (PM053) were purchased from Santa Cruz Biotechnology (Dallas, TX, USA) and Medical \& Biological Laboratories (Nagoya, Japan), respectively.

Growth curves: Cells were seeded in 24-well plates with 500 $\mu \mathrm{l}$ complete medium at a density of 2,000 cells per well, and cultured for 7 days. Relative viable cell numbers were determined by crystal violet staining every $24 \mathrm{~h}$ after seeding as described elsewhere (17).

Soft-agar colony-formation assay: A soft-agar colony-formation assay was performed as described elsewhere (18). Colonies consisting of more than 50 cells were counted. All assays were performed in triplicate and repeated three times.

Drug sensitivity analysis: 5-Fluorouracil (5-FU), cisplatin, and oxaliplatin were chosen because these are the most widely accepted first-line regimen drugs for patients with advanced GC. 5FU was purchased from Kyowa Hakko Kirin (Tokyo, Japan); cisplatin and oxaliplatin were purchased from Wako (Osaka, Japan). The relative cell viability was determined by the 3-(4,5dimethylthiazol-2-yl)-2,5-diphenyltetrazolium bromide assay (Dojindo, Kumamoto, Japan) as described elsewhere (19).

Statistical analysis. OS, DFS, and PFS were estimated using the Kaplan-Meier method, and compared using the log-rank test. Multivariable regression analyses were performed using the Cox proportional hazards model to examine the association between patient background factors and survival using the forward stepwise selection (likelihood ratio) method. A propensity score-matched analysis was performed to reduce bias due to confounding variables. The propensity score was calculated using a multivariable logistic regression model. A 1:1 propensity score matching was performed using the nearest-neighbor matching method. Patient backgrounds were compared between groups using the chi-squared test. The $t$-test was used to evaluate the effect of MDM4 expression on the drug sensitivity. Two-sided $p$ values of less than 0.05 were considered significant. Statistical analyses were performed using the IBM SPSS software, version 25 (IBM, Armonk, NY, USA).

\section{Results}

Background factors and survival of all patients. Clinical data and tumor tissue samples were collected from 241 patients with stage I-IV GC. The specimens of 146 patients with stage I-III GC were obtained from surgical resections of GC; the specimens of 95 patients with stage IV disease were mainly obtained from endoscopic biopsies and all these patients had received systemic chemotherapies. The first-line regimens were $\mathrm{S}-1$ plus cisplatin in $45, \mathrm{~S}-1$ in $25, \mathrm{~S}-1$ plus oxaliplatin in eight, FOLFOX (5-FU plus levofolinate plus oxaliplatin) in eight, docetaxel plus cisplatin plus S-1 in three, and other types in six. 




Figure 1. Representative immunohistochemical staining images for p53, murine double minute (MDM) 2, and MDM4 with 0-25\%, 26-50\%, 51-75\% and $76-100 \%$ positive tumor nuclei, respectively. Scale bars indicate $20 \mu \mathrm{m}$.

Survival of patients with stage I-III GC. The median duration of follow-up for patients with stage I-III GC was 5.2 years (range $=0.1-11.5$ years). The 5-year OS rate [95\% confidence interval (CI)] was $74 \%(66-81 \%)$. The 5 -year DFS rate was $68 \%(60-76 \%)$. The multivariable analysis for OS showed that high stage [hazard ratio $(\mathrm{HR})=4.5,95 \% \mathrm{CI}=2.0-10.4$; $p<0.001]$ and $\mathrm{p} 53$ expression $(\mathrm{HR}=2.3,95 \% \mathrm{CI}=1.0-5.2$; $p=0.047$ ) were independent prognostic factors (Table I). Similarly, high stage $(\mathrm{HR}=5.0,95 \% \mathrm{CI}=2.3-10.7 ; p<0.001)$ and $\mathrm{p} 53$ expression $(\mathrm{HR}=2.3,95 \% \mathrm{CI}=1.1-4.9 ; p=0.025)$ were independent prognostic factors for DFS.

Survival of patients with stage IV GC. The median duration of follow-up of patients with stage IV GC was 21 months (range $=1.3-78.2$ months). The median OS was $18(95 \%$ $\mathrm{CI}=13-21)$ months, while the median PFS was $6.5(95 \%$ $\mathrm{CI}=5.5-7.5)$ months. The multivariable analysis for $\mathrm{OS}$ showed that only high p53 expression $(\mathrm{HR}=2.3,95 \%$ $\mathrm{CI}=1.3-4.1 ; p=0.006)$ was an independent prognostic factor (Table II). The Eastern Cooperative Oncology Group performance status $(\mathrm{HR}=1.8,95 \% \mathrm{CI}=1.1-2.8 ; p=0.014)$ and p53 expression $(\mathrm{HR}=1.9,95 \% \mathrm{CI}=1.2-3.0 ; p=0.007)$ were independent prognostic factors for PFS.
Background factors and survival of patients with GC with low expression of p53. The number of patients with GC with low expression of p53 was 119 in the group with stage I-III and 54 in that the stage IV disease. The first-line chemotherapy regimens were S-1 plus cisplatin in $25, \mathrm{~S}-1$ in 14 , FOLFOX in five, $\mathrm{S}-1$ plus oxaliplatin in four, $\mathrm{S}-1$ plus cisplatin plus trastuzumab in three, docetaxel plus cisplatin plus $\mathrm{S}-1$ in two, and irinotecan plus cisplatin in one. The proportion of patients with high expression of MDM2 increased gradually with disease progression, while that of patients with high expression of MDM4 decreased (Figure 2).

Survival of patients with stage I-III disease with low expression of $p 53$. The 5-year OS rate was $77(95 \%$ $\mathrm{CI}=67-85 \%)$, while the 5-year DFS rate was $73(95 \%$ $\mathrm{CI}=63-81 \%)$. Although MDM4 was not a significant factor in the univariable analysis for OS $(p=0.72)$, the multivariable analysis for OS showed that MDM4 was an independent prognostic factor $(\mathrm{HR}=2.7,95 \% \mathrm{CI}=1.1-6.4$; $p=0.027)$ in addition to stage $(\mathrm{HR}=10,95 \% \mathrm{CI}=3.3-32.2$; $p<0.001$ ) (Table III). Stage was also an independent significant prognostic factor $(\mathrm{HR}=7.0,95 \% \mathrm{CI}=2.6-18.8$; $p<0.001)$ for DFS. 
Table I. Background factors and survival analysis for 146 patients with stage I-III gastric cancer.

\begin{tabular}{|c|c|c|c|c|c|c|c|c|c|c|c|c|}
\hline \multirow[t]{3}{*}{ Variable } & \multirow[b]{3}{*}{ Comparison } & \multirow[b]{3}{*}{$\begin{array}{c}\text { Number of } \\
\text { patients }\end{array}$} & \multicolumn{5}{|c|}{ Overall survival } & \multicolumn{5}{|c|}{ Disease-free survival } \\
\hline & & & \multicolumn{2}{|c|}{$\begin{array}{c}\text { Univariate } \\
\text { analysis }\end{array}$} & \multicolumn{3}{|c|}{ Multivariate analysis } & \multicolumn{2}{|c|}{$\begin{array}{l}\text { Univariate } \\
\text { analysis }\end{array}$} & \multicolumn{3}{|c|}{ Multivariate analysis } \\
\hline & & & HR & $p$-Value & $\mathrm{HR}$ & $95 \% \mathrm{CI}$ & $p$-Value & HR & $p$-Value & HR & $95 \%$ CI & $p$-Value \\
\hline Gender & Male $v s$. female & $103 / 43$ & 0.95 & 0.89 & & & & 1.15 & 0.69 & & & \\
\hline Age & $>65 v s . \leq 65$ years & $64 / 82$ & 1.05 & 0.89 & & & & 1.01 & 0.99 & & & \\
\hline Tumor size & $>50 \mathrm{vs} . \leq 50 \mathrm{~mm}$ & $70 / 76$ & 1.66 & 0.12 & & & & 1.89 & 0.03 & & & \\
\hline Adjuvant chemotherapy & Yes $v s$. no & $76 / 70$ & 3.03 & 0.002 & & & & 2.74 & 0.001 & & & \\
\hline Histology & Diffuse $v s$. intestinal & $75 / 71$ & 1.82 & 0.08 & & & & 1.61 & 0.12 & & & \\
\hline ECOG PS & $1 / 2 v s .0$ & $61 / 70$ & 1.21 & 0.59 & & & & 1.35 & 0.35 & & & \\
\hline Stage & III $v s . \mathrm{I} / \mathrm{II}$ & $79 / 67$ & 4.35 & $<0.001$ & 4.54 & $1.98-10.41$ & $<0.001$ & 4.96 & $<0.001$ & 4.98 & $2.30-10.74$ & $<0.001$ \\
\hline CEA & Abnormal vs. normal & $25 / 115$ & 1.93 & 0.08 & & & & 1.71 & 0.13 & & & \\
\hline p53 & High vs. low & $27 / 119$ & 2.42 & 0.01 & 2.30 & $1.01-5.21$ & 0.047 & 2.61 & 0.003 & 2.33 & $1.11-4.88$ & 0.025 \\
\hline MDM2 & High vs. low & $73 / 73$ & 1.87 & 0.06 & & & & 1.93 & 0.03 & & & \\
\hline MDM4 & High $v s$. low & $59 / 87$ & 0.82 & 0.57 & & & & 0.86 & 0.62 & & & \\
\hline
\end{tabular}

CEA: Carcinoembryonic antigen; ECOG PS: Eastern Cooperative Oncology Group performance status; MDM2/4: murine double minute 2/4.

Table II. Background factors and survival analysis for 95 gastric cancer patients with stage IV cancer.

\begin{tabular}{|c|c|c|c|c|c|c|c|c|c|c|c|c|}
\hline \multirow[t]{3}{*}{ Variable } & \multirow[b]{3}{*}{ Comparison } & \multirow[b]{3}{*}{$\begin{array}{c}\text { Number of } \\
\text { patients }\end{array}$} & \multicolumn{5}{|c|}{ Overall survival } & \multicolumn{5}{|c|}{ Progression-free survival } \\
\hline & & & \multicolumn{2}{|c|}{$\begin{array}{c}\text { Univariate } \\
\text { analysis }\end{array}$} & \multicolumn{3}{|c|}{ Multivariate analysis } & \multicolumn{2}{|c|}{$\begin{array}{c}\text { Univariate } \\
\text { analysis }\end{array}$} & \multicolumn{3}{|c|}{ Multivariate analysis } \\
\hline & & & HR & $p$-Value & HR & $95 \% \mathrm{CI}$ & $p$-Value & HR & $p$-Value & HR & $95 \% \mathrm{CI}$ & $p$-Value \\
\hline Gender & Male $v s$. female & $74 / 21$ & 1.08 & 0.82 & & & & 1.48 & 0.14 & & & \\
\hline Age & $>65$ vs. $\leq 65$ years & $42 / 53$ & 0.99 & 0.98 & & & & 1.16 & 0.51 & & & \\
\hline Histology & Diffuse $v s$. intestinal & $61 / 34$ & 1.35 & 0.33 & & & & 1.28 & 0.28 & & & \\
\hline ECOG PS & $1 / 2$ vs. 0 & $44 / 51$ & 1.75 & 0.06 & & & & 1.91 & 0.005 & 1.78 & $1.12-2.83$ & 0.014 \\
\hline CEA & Abnormal vs. normal & $44 / 51$ & 1.12 & 0.70 & & & & 1.05 & 0.83 & & & \\
\hline Sites of metastasis & $>1$ vs. 1 & $62 / 33$ & 1.10 & 0.75 & & & & 1.13 & 0.59 & & & \\
\hline p53 & High $v s$. low & $41 / 54$ & 2.29 & 0.005 & 2.29 & $1.26-4.14$ & 0.006 & 1.20 & 0.002 & 1.88 & $1.19-2.97$ & 0.007 \\
\hline MDM2 & High $v s$. low & $67 / 28$ & 1.50 & 0.24 & & & & 1.28 & 0.32 & & & \\
\hline MDM4 & High $v s$. low & $24 / 71$ & 1.48 & 0.26 & & & & 1.45 & 0.16 & & & \\
\hline
\end{tabular}

CEA: Carcinoembryonic antigen; ECOG PS: Eastern Cooperative Oncology Group performance status; MDM2/4: murine double minute 2/4.

The patients were divided into two groups with high and low expression of MDM4, and a propensity score-matched analysis was performed to reduce the bias, especially the influence of stage. After 1:1 propensity score matching, 62 patients were selected: 31 patients with high expression and 31 patients with low expression of MDM4. The patient backgrounds of the two matched groups were well-balanced, including stage $(p=0.41)$ (Table IV). OS was significantly shorter in the group with high expression of MDM4 than in that with low expression $(\mathrm{HR}=5.1,95 \% \quad \mathrm{CI}=1.1-23.7$; $p=0.02$ ) (Figure 3).
Survival of patients with stage IV disease with low expression of $p 53$. The median OS was 24 (95\% CI=14-34) months, and the median PFS was 7.9 (95\% CI=6.3-9.5) months. The multivariable analysis for OS showed that MDM4 was the only significant independent prognostic factor $(\mathrm{HR}=6.2,95 \% \mathrm{CI}=2.2-17.6 ; p=0.001)$ (Table V). For PFS, the Eastern Cooperative Oncology Group performance states was a significant independent prognostic factor $(\mathrm{HR}=2.0,95 \% \mathrm{CI}=1.1-3.9 ; p=0.03)$. Figure 4 shows the Kaplan-Meier curves of OS for the three groups with: A: Low expression of p53 and low expression of MDM4; B: 


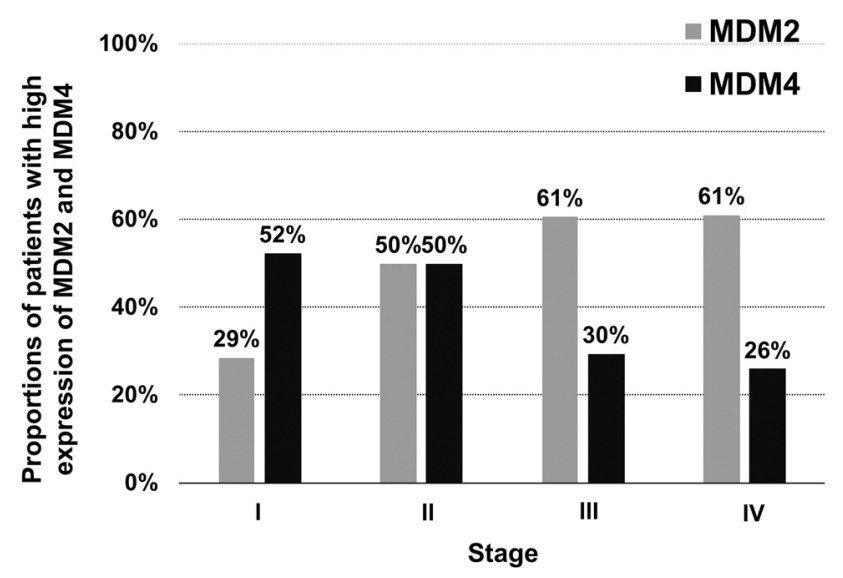

Figure 2. Expression status of murine double minute (MDM) 2 and MDM4 in patients with gastric cancer with low expression of $p 53$. The proportion of patients with high expression of MDM2 increased gradually from stage I to stage $I V$, while that of patients with high expression of MDM4 decreased.

low expression of p53 and high expression of MDM4; and $\mathrm{C}$ : high expression of $\mathrm{p} 53$. The OS of group B was significantly shorter than that of group A $(\mathrm{HR}=6.2,95 \%$ $\mathrm{CI}=2.2-17.6 ; p<0.001)$. The OS durations of groups $\mathrm{B}$ and $\mathrm{C}$ were similar $(\mathrm{HR}=1.3,95 \% \mathrm{CI}=0.6-3.1 ; p=0.54)$.

Cell proliferation and drug resistance of MDM4-transduced NUGC4 cells. MDM4-NUGC4 cells expressed a nearly 24fold higher level of MDM4 than EGFP-NUGC4 cells (control cells) (Figure 5). In the conventional plate culture, both control and MDM4-NUGC4 cells grew similarly, with a doubling time of $48 \mathrm{~h}$. In the soft-agar culture, MDM4NUGC4 cells formed twofold more colonies than the control cells $(193 \pm 37$ vs. $101 \pm 13, p<0.02)$.

In the drug-sensitivity analysis (Figure 6), the $50 \%$ inhibitory concentration $\left(\mathrm{IC}_{50}\right)$ of 5-FU and oxaliplatin in the MDM4-NUGC4 cells were 5.3-fold and 3.5-fold higher than those for the control cells, respectively. The $\mathrm{IC}_{50}$ for cisplatin was similar in MDM4-NUGC4 and control cells.

\section{Discussion}

Since p53 IHC positivity is a prognostic marker in various cancer types including GC, we examined whether expression of MDM2 and MDM4 might also be useful markers in GC, especially in WT TP53 GC. We confirmed that p53 was a prognostic factor for our patients with GC, but did not find any relationship between MDM4 expression and prognosis when all the patients were analyzed. However, among the patients with low expression of p53, those with high MDM4 expression had significantly shorter OS than those with low expression of MDM4. To our knowledge, this is the first report to show that MDM4 is a poor prognostic marker in patients with GC with low expression of p53.

The multivariable analysis including all the patients showed that those with high expression of p53 had significantly shorter survival than those with low expression of p53, suggesting that p53-positive staining indicates poor prognosis. This result is consistent with the findings of other reports (20-22). Without any stresses - such as genotoxicity, nutrient deficiency, and hypoxia - normal p53 is degraded by MDM2 to levels undetectable by IHC (23). Therefore, the state of low expression of p53 could be considered a surrogate for WT TP53.

Among patients with stage IV disease, those with low expression of p53 and high expression of MDM4 had similar OS to those with high p53 expression. This might suggest that normal p53 function was almost suppressed by high expression of MDM4. However, MDM4 expression has not yet been explicitly reported to be a poor prognostic marker for GC. To date, only one study has shown MDM4 expression to be associated with lymph node metastasis, which is an independent prognostic factor of GC regardless of p53 staining pattern (24). In our study, we focused on the biological role of MDM4 and found direct evidence to show that MDM4 was an independent poor prognostic factor in patients with low p53 expression in GC.

In such patients, high expression of MDM2 was associated with advanced tumor stage. This finding was comparable to those of other reports $(11,21,22)$. In contrast, high expression of MDM4 was inversely associated with tumor stage. A previous study reported results opposite to ours on the association between MDM4 expression and stage (24). The reason for this discrepancy is unclear; however, our finding might be explained by the loss of phosphatase and tensin homolog (PTEN) function. PTEN is a tumor-suppressor protein that negatively regulates MDM2 (25, 26). Loss of PTEN function induces MDM2 accumulation, and MDM2 can degrade not only p53 but also MDM4 (27). The mutations of PTEN and TP53 are mutually exclusive, and loss of PTEN expression has been frequently reported in advanced GC (28). MDM4-positive patients with GC may lose PTEN function, resulting in MDM2 accumulation and reduced MDM4 expression with disease progression. Future studies are warranted to investigate the relationship between PTEN and MDM4 in patients with GC with low p53 expression to understand the exact mechanism of MDM4 expression.

We previously reported that knockdown of MDM4 weakly increased p53 activity and caused marginal growth suppression in the NUGC4 cell line with relatively low expression of MDM4, but caused intense p53 activation and potent growth inhibition in the MDM4-amplified MCF-7 breast cancer cell line (29). This suggests that MDM4 may have an expression leveldependent negative effect on p53 activity. To strengthen our clinical findings in this study, we evaluated the effects of MDM4 overexpression on tumor cell growth and sensitivity to cytotoxic drugs using NUGC4 cells. MDM4 transduction 
Table III. Background factors and survival analysis for 119 patients with stage I-III gastric cancer and low expression of p53.

\begin{tabular}{|c|c|c|c|c|c|c|c|c|c|c|c|c|}
\hline \multirow[t]{3}{*}{ Variable } & \multirow[b]{3}{*}{ Comparison } & \multirow[b]{3}{*}{$\begin{array}{c}\text { Number of } \\
\text { patients }\end{array}$} & \multicolumn{5}{|c|}{ Overall survival } & \multicolumn{5}{|c|}{ Disease-free survival } \\
\hline & & & \multicolumn{2}{|c|}{$\begin{array}{c}\text { Univariate } \\
\text { analysis }\end{array}$} & \multicolumn{3}{|c|}{ Multivariate analysis } & \multicolumn{2}{|c|}{$\begin{array}{l}\text { Univariate } \\
\text { analysis }\end{array}$} & \multicolumn{3}{|c|}{ Multivariate analysis } \\
\hline & & & HR & $p$-Value & HR & $95 \% \mathrm{CI}$ & $p$-Value & HR & $p$-Value & HR & $95 \%$ CI & $p$-Value \\
\hline Gender & Male $v s$. female & $81 / 38$ & 0.73 & 0.42 & & & & 0.84 & 0.64 & & & \\
\hline Age & $>65 v s . \leq 65$ Years & $50 / 69$ & 1.14 & 0.73 & & & & 0.95 & 0.89 & & & \\
\hline Tumor size & $>50 v s . \leq 50 \mathrm{~mm}$ & $56 / 63$ & 1.94 & 0.08 & & & & 1.92 & 0.06 & & & \\
\hline Adjuvant chemotherapy & Yes vs. no & $61 / 58$ & 5.07 & $<0.001$ & & & & 3.42 & 0.001 & & & \\
\hline Histology & Diffuse $v s$. intestinal & $64 / 55$ & 1.83 & 0.14 & & & & 1.75 & 0.13 & & & \\
\hline ECOG PS & $1 / 2$ vs. 0 & $51 / 58$ & 1.01 & 0.99 & & & & 1.20 & 0.63 & & & \\
\hline Stage & III $v s . \mathrm{I} / \mathrm{II}$ & $61 / 58$ & 6.25 & $<0.001$ & 10.27 & $3.28-32.16$ & $<0.001$ & 6.18 & $<0.001$ & 7.04 & $2.63-18.83$ & $<0.001$ \\
\hline CEA & Abnormal vs. normal & $20 / 93$ & 1.76 & 0.22 & & & & 1.37 & 0.48 & & & \\
\hline MDM2 & High $v s$. low & $57 / 62$ & 1.73 & 0.16 & & & & 1.69 & 0.14 & & & \\
\hline MDM4 & High $v s$. low & $48 / 71$ & 1.15 & 0.72 & 2.68 & $1.12-6.44$ & 0.027 & 0.99 & 0.98 & & & \\
\hline
\end{tabular}

CEA: Carcinoembryonic antigen; ECOG PS: Eastern Cooperative Oncology Group performance status; MDM2/4: murine double minute 2/4.

Table IV. Characteristics of patients with stage I-III gastric cancer and low expression of p53 in a propensity score-matched analysis.

\begin{tabular}{|c|c|c|c|c|c|c|c|}
\hline \multirow[t]{3}{*}{ Variable } & \multirow{3}{*}{ Comparison } & \multicolumn{3}{|c|}{ Before matching $(\mathrm{n}=119)$} & \multicolumn{3}{|c|}{ After matching $(\mathrm{n}=62)$} \\
\hline & & \multicolumn{2}{|c|}{ MDM4 expression, n (\%) } & \multirow[t]{2}{*}{$p$-Value } & \multicolumn{2}{|c|}{ MDM4 expression, n (\%) } & \multirow[t]{2}{*}{$p$-Value } \\
\hline & & High & Low & & High & Low & \\
\hline Gender & Male $v s$. female & $34(71) / 14(29)$ & $47(66) / 24(34)$ & 0.60 & $18(58) / 13(42)$ & $19(61) / 12(39)$ & 0.80 \\
\hline Age & $>65 v s . \leq 65$ years & $25(52) / 23(48)$ & $44(62) / 27(38)$ & 0.28 & $18(58) / 13(42)$ & $19(61) / 12(39)$ & 0.80 \\
\hline Tumor size & $>50 \mathrm{vs} . \leq 50 \mathrm{~mm}$ & $26(54) / 22(46)$ & $37(52) / 34(48)$ & 0.83 & $18(58) / 13(42)$ & $20(65) / 11(36)$ & 0.60 \\
\hline Adjuvant chemotherapy & Yes $v s$. no & $18(38) / 30(62)$ & $43(61) / 28(39)$ & 0.014 & $12(39) / 19(61)$ & $11(36) / 20(64)$ & 0.79 \\
\hline Stage & I, II $v s$. III & $30(63) / 18(38)$ & $28(39) / 43(61)$ & 0.014 & $17(55) / 14(45)$ & $22(71) / 9(29)$ & 0.41 \\
\hline ECOG PS & $0 v s .1,2$ & $19(40) / 28(60)$ & $39(63) / 23(37)$ & 0.02 & $30(97) / 1(3)$ & $30(97) / 1(3)$ & 0.75 \\
\hline CEA & Abnormal vs. normal & $11(23) / 36(77)$ & $9(14) / 57(86)$ & 0.18 & $6(19) / 25(81)$ & $4(13) / 27(87)$ & 0.49 \\
\hline Histology & Intestinal $v s$. diffuse & $23(48) / 25(52)$ & $32(45) / 39(55)$ & 0.76 & $13(42) / 18(58)$ & $16(52) / 15(48)$ & 0.45 \\
\hline MDM2 expression & High $v s$. low & $26(54) / 22(46)$ & $32(45) / 39(55)$ & 0.26 & $13(42) / 18(58)$ & $11(36) / 20(64)$ & 0.60 \\
\hline
\end{tabular}

CEA: Carcinoembryonic antigen; ECOG PS: Eastern Cooperative Oncology Group performance status; MDM2/4: murine double minute 2/4. For comparison of patient backgrounds between groups $p$-Value was conducted using the chi-square test.

enhanced anchorage-independent cell growth as compared to the control cells, showing that MDM4 overexpression induced more potent tumor-forming activity. Moreover, MDM4 overexpression provided NUGC4 cells with resistance to 5-FU and oxaliplatin but not to cisplatin. Oxaliplatin contains the 1,2diaminocyclohexane carrier ligand, whereas cisplatin does not. Oxaliplatin represses transcription of genes involved in thymidylate synthesis using the 1,2-diaminocyclohexane carrier ligand in a p53 expression level-dependent manner (30). Resistance to oxaliplatin and 5-FU is most likely mediated by MDM4-induced p53 inactivation (31). Since these two drugs are frequently used as standard first-line chemotherapy, this resistance may partly explain why patients with stage IV disease with high MDM4 expression had significantly shorter OS compared to those with low MDM4 expression. Interestingly, MDM4 overexpression had no effect on sensitivity to cisplatin. This may indicate that chemotherapy for GC including cisplatin benefits patients with low p53 and high MDM4 expression. Therefore, we tried to analyze differences in PFS between patients administered oxaliplatin-based and cisplatin-based chemotherapies. However, this comparison was not possible because of the small number of patients.

This study had some methodological limitations. Firstly, there would have been unexpected bias due to the retrospective nature of the study. Secondly, because of a small number of patients, we were unable to judge whether survival was 


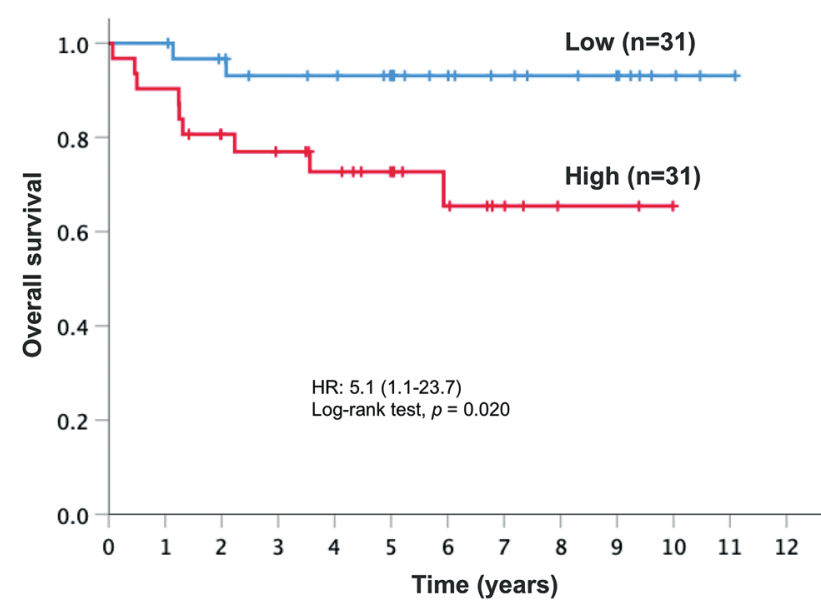

Figure 3. Overall survival (OS) of patients with stage I-III gastric cancer with low expression of $p 53$, adjusted using the propensity scorematched method. Patients were divided into two groups according to murine double minute (MDM) 4 expression. The 5-year OS rate of patients with high MDM4 expression was 73\% [95\% confidence interval $(C I)=63-81 \%]$, and that of patients with low MDM4 expression was 93\% (95\% CI=86-97\%). Patients with high MDM4 expression had shorter OS than those with low MDM4 expression (hazard ratio=5.1, 95\% $C I=1.1-23.7 ; p=0.020$ ).

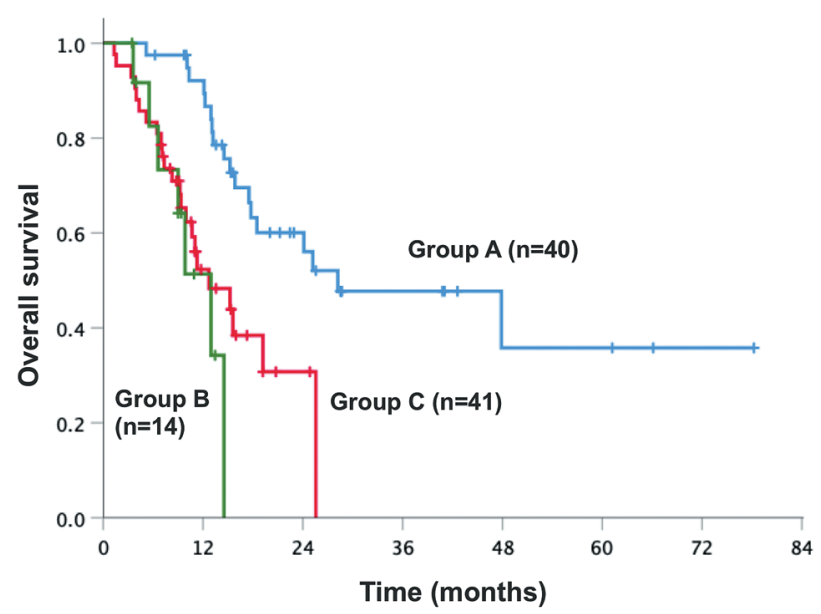

Figure 4. Overall survival (OS) of patients with stage IV disease. Patients were divided into groups by expression pattern: Group A, patients with low p53 and low murine double minute (MDM) 4 expression, median OS was 28 (95\% confidence interval [CI]=7.0-49.4) months; group B, patients with low p53 expression and high MDM4 expression, median OS was 13 (95\% CI=6.9-19.2) months; and group $C$, patients with high $p 53$ expression, median OS was 13 (95\% CI=6.718.7) months. Group B had shorter OS than group A (hazard ratio=6.2, 95\% CI=2.2-17.6; $p<0.001)$. Survival curves were similar for groups $B$ and $C$ (hazard ratio $=1.3,95 \% C I=0.6-3.1 ; p=0.538)$.

Table V. Background factors and survival analysis for 54 patients with stage IV gastric cancer and low expression of p53.

\begin{tabular}{|c|c|c|c|c|c|c|c|c|c|c|c|c|}
\hline \multirow[t]{3}{*}{ Variable } & \multirow[b]{3}{*}{ Comparison } & \multirow[b]{3}{*}{$\begin{array}{c}\text { Number of } \\
\text { patients }\end{array}$} & \multicolumn{5}{|c|}{ Overall survival } & \multicolumn{5}{|c|}{ Progression-free survival } \\
\hline & & & \multicolumn{2}{|c|}{$\begin{array}{c}\text { Univariable } \\
\text { analysis }\end{array}$} & \multicolumn{3}{|c|}{ Multivariable analysis } & \multicolumn{2}{|c|}{$\begin{array}{c}\text { Univariable } \\
\text { analysis }\end{array}$} & \multicolumn{3}{|c|}{ Multivariable analysis } \\
\hline & & & HR & $p$-Value & HR & $95 \% \mathrm{CI}$ & $p$-Value & HR & $p$-Value & HR & $95 \% \mathrm{CI}$ & $p$-Value \\
\hline Gender & Male $v s$. female & $39 / 15$ & 0.87 & 0.76 & & & & 1.28 & 0.47 & & & \\
\hline Age & $>65$ vs. $\leq 65$ years & $21 / 33$ & 0.75 & 0.50 & & & & 1.13 & 0.70 & & & \\
\hline Histology & Diffuse $v s$. intestinal & $30 / 24$ & 1.01 & 0.99 & & & & 0.98 & 0.95 & & & \\
\hline ECOG PS & $1 / 2$ vs. 0 & $22 / 32$ & 1.63 & 0.25 & & & & 2.02 & 0.03 & 2.02 & $1.06-3.86$ & 0.033 \\
\hline CEA & Abnormal vs. normal & $23 / 31$ & 1.29 & 0.54 & & & & 0.89 & 0.70 & & & \\
\hline Sites of metastasis & $>1$ vs. 1 & $31 / 23$ & 1.06 & 0.89 & & & & 0.98 & 0.95 & & & \\
\hline MDM2 & High $v s$. low & $33 / 21$ & 0.94 & 0.88 & & & & 1.23 & 0.52 & & & \\
\hline MDM4 & High vs. low & $14 / 40$ & 6.21 & $<0.001$ & 6.21 & $2.20-17.58$ & 0.001 & 1.90 & 0.09 & & & \\
\hline
\end{tabular}

CEA: Carcinoembryonic antigen; CI: confidence intervaI; ECOG PS: Eastern Cooperative Oncology Group performance status; HR: hazard ratio; MDM2/4: murine double minute 2/4.

influenced by factors such as chemotherapy regimens in addition to the variables discussed in this article. Thirdly, we did not perform gene sequencing to determine the TP53 genotype. However, we divided p53 status into two categories by IHC and obtained significant prognostic results. We consider that the IHC method can be used as an alternative to the gene sequencing method of TP53. Finally, an optimal cutoff percentage of positively stained cells was not fully established in this study. We set candidate cutoff percentages of $25 \%, 50 \%$, and $75 \%$ for each marker studied and tried to analyze survival (data not shown). As a result, the cutoff percentage in the present study seemed appropriate for our analysis.

In conclusion, we demonstrated the role of MDM4 as a factor indicating poor prognosis for patients with GC with low expression of p53. MDM4 may be a promising drug target in patients with GC with low p53 and high MDM4 expression. 

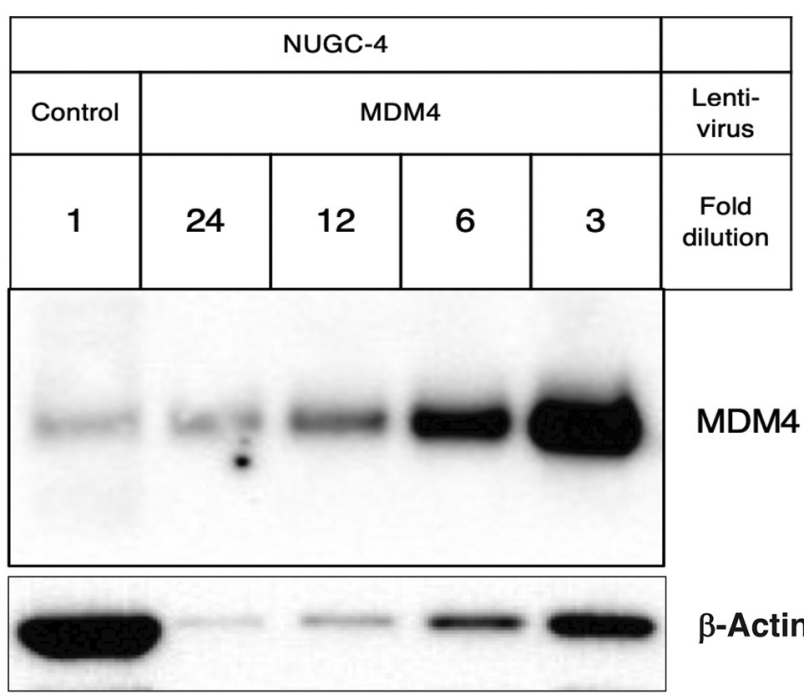

$\beta$-Actin

Figure 5. Expression of murine double minute (MDM) 4 in MDM4transduced NUGC4 cells. MDM4-transfected cells expressed a level of MDM4 nearly 24-fold higher than the control cells.

\section{Conflicts of Interest}

The Authors have no conflicts of interest.

\section{Authors' Contributions}

All Authors contributed to the study conception and design. XZ, YY, $\mathrm{XW}, \mathrm{MS}, \mathrm{MI}, \mathrm{AS}, \mathrm{MH}, \mathrm{SE}$, and TM collected clinical materials and data. XZ, YY, XW, MI, and KY performed laboratory experiments and analysis. XZ analyzed statistics and wrote the article. YY, TM, $\mathrm{KY}$ and $\mathrm{IH}$ reviewed the data and analysis, and revised the article. All Authors have read and approved the final article.

\section{Acknowledgements}

The Authors would like to thank Dr. F. Miyamasu at the Medical English Communication Center, University of Tsukuba, and Editage (www.editage.com) for English language editing. This work was supported by JSPS KAKENHI grant number JP18K07288.

\section{References}

1 Cancer Genome Atlas Research N: Comprehensive molecular characterization of gastric adenocarcinoma. Nature 513(7517): 202-209, 2014. PMID: 25079317. DOI: 10.1038/nature13480

2 Merkel O, Taylor N, Prutsch N, Staber PB, Moriggl R, Turner SD and Kenner L: When the guardian sleeps: Reactivation of the p53 pathway in cancer. Mutat Res 773: 1-13, 2017. PMID: 28927521. DOI: 10.1016/j.mrrev.2017.02.003

3 Wade M, Wang YV and Wahl GM: The p53 orchestra: Mdm2 and Mdmx set the tone. Trends Cell Biol 20(5): 299-309, 2010. PMID: 20172729. DOI: 10.1016/j.tcb.2010.01.009
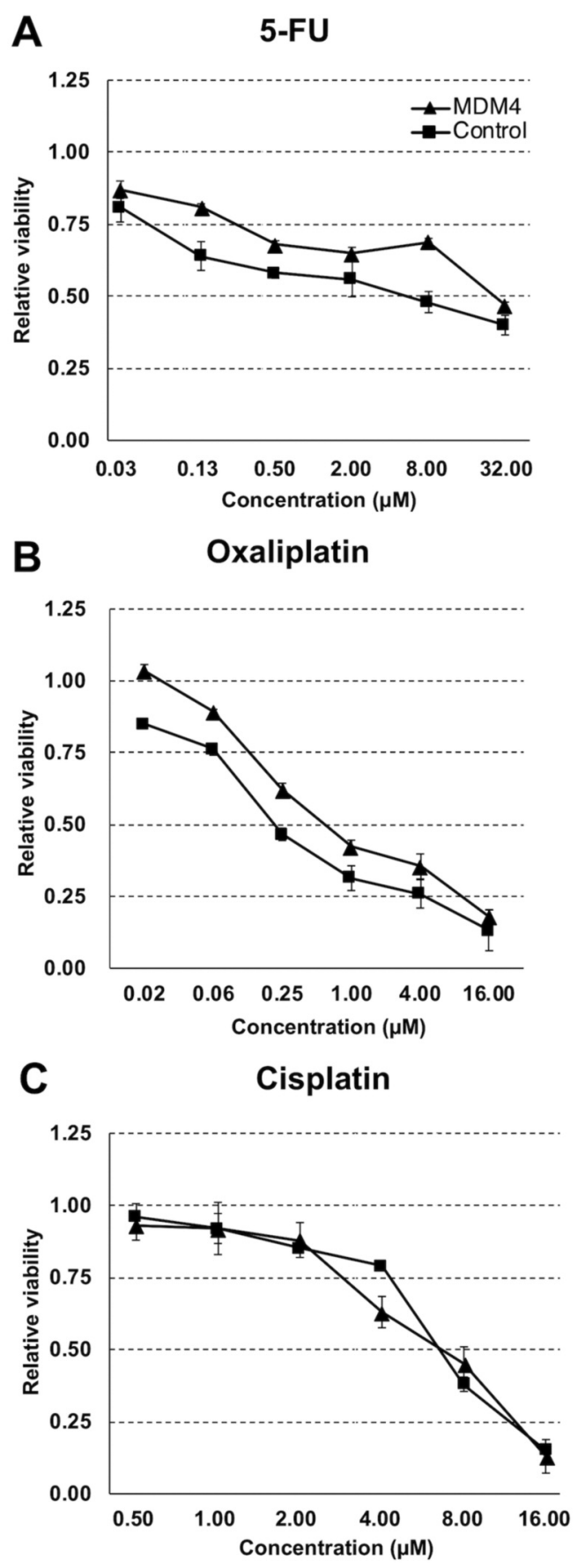

Figure 6. Cell viability assay and effect of murine double minute (MDM) 4 overexpression on sensitivity to different cytotoxic drugs. A: 5-Fluorouracil; B: oxaliplatin; C: cisplatin.

4 Brown CJ, Lain S, Verma CS, Fersht AR and Lane DP: Awakening guardian angels: drugging the 553 pathway. Nat Rev Cancer 9(12): 862-873, 2009. PMID: 19935675. DOI: 10.1038/nrc2763

5 Wu X, Bayle JH, Olson D and Levine AJ: The p53-MDM-2 autoregulatory feedback loop. Genes Dev 7(7A): 1126-1132, 1993. PMID: 8319905. DOI: 10.1101/gad.7.7a.1126 
6 Juven-Gershon T and Oren M: Mdm2: The ups and downs. Mol Med 5(2): 71-83, 1999. PMID: 10203572. DOI: 10.1007/ bf03402141

7 Freedman DA, Wu L and Levine AJ: Functions of the MDM2 oncoprotein. Cell Mol Life Sci 55(1): 96-107, 1999. PMID: 10065155. DOI: $10.1007 / \mathrm{s} 000180050273$

8 Francoz S, Froment P, Bogaerts S, De Clercq S, Maetens M, Doumont G, Bellefroid E and Marine JC: Mdm4 and Mdm2 cooperate to inhibit p53 activity in proliferating and quiescent cells in vivo. Proc Natl Acad Sci USA 103(9): 3232-3237, 2006. PMID: 16492744. DOI: 10.1073/pnas.0508476103

9 Tanimura S, Ohtsuka S, Mitsui K, Shirouzu K, Yoshimura A and Ohtsubo M: MDM2 interacts with MDMX through their ring finger domains. FEBS Lett 447(1): 5-9, 1999. PMID: 10218570. DOI: 10.1016/s0014-5793(99)00254-9

10 Uldrijan S, Pannekoek WJ and Vousden KH: An essential function of the extreme C-terminus of MDM2 can be provided by MDMX. EMBO J 26(1): 102-112, 2007. PMID: 17159902. DOI: $10.1038 /$ sj.emboj.7601469

11 Ye Y, Li X, Yang JJ, Miao SH, Wang SY, Chen YS, Xia XW, Wu XM, Zhang JB, Zhou Y, He S, Tan YF, Qiang FL, Li G, Roe OD and Zhou JW: MDM2 is a useful prognostic biomarker for resectable gastric cancer. Cancer Science 104(5): 590-598, 2013. PMID: 23347235. DOI: 10.1111/cas.12111

12 Sano T and Aiko T: New Japanese classifications and treatment guidelines for gastric cancer: revision concepts and major revised points. Gastric Cancer 14(2): 97-100, 2011. PMID: 21573921. DOI: 10.1007/s10120-011-0040-6

13 Han JY, Lee GK, Jang DH, Lee SY and Lee JS: Association of p53 codon 72 polymorphism and MDM2 SNP309 with clinical outcome of advanced nonsmall cell lung cancer. Cancer 113(4): 799-807, 2008. PMID: 18618574. DOI: $10.1002 / \mathrm{cncr} .23668$

14 Wang YC, Lin RK, Tan YH, Chen JT, Chen CY and Wang YC: Wild-type p53 overexpression and its correlation with MDM2 and p14ARF alterations: An alternative pathway to non-smallcell lung cancer. J Clin Oncol 23(1): 154-164, 2005. PMID: 15625370. DOI: 10.1200/JCO.2005.03.139

15 Uchida C, Miwa S, Isobe T, Kitagawa K, Hattori T, Oda T, Yasuda $\mathrm{H}$ and Kitagawa M: Effects of Mdmx and Mdm2mediated downregulation of pRB. FEBS Lett 580(7): 1753-1758, 2006. PMID: 16510145. DOI: 10.1016/j.febslet.2006.02.029

16 Imanishi M, Yamamoto Y, Wang X, Sugaya A, Hirose M, Endo S, Natori Y, Yamato $\mathrm{K}$ and Hyodo I: Augmented antitumor activity of 5-fluorouracil by double knockdown of MDM4 and MDM2 in colon and gastric cancer cells. Cancer Sci 110(2): 639649, 2019. PMID: 30488540. DOI: 10.1111/cas.13893

17 Feoktistova M, Geserick P and Leverkus M: Crystal violet assay for determining viability of cultured cells. Cold Spring Harb Protoc 2016(4): pdb prot087379, 2016. PMID: 27037069. DOI: 10.1101/pdb.prot087379

18 Yoshinouchi M, Yamada T, Kizaki M, Fen J, Koseki T, Ikeda Y, Nishihara $\mathrm{T}$ and Yamato $\mathrm{K}$ : In vitro and in vivo growth suppression of human papillomavirus 16-positive cervical cancer cells by E6 siRNA. Mol Ther 8(5): 762-768, 2003. PMID: 14599809. DOI: 10.1016/j.ymthe.2003.08.004

19 Yamato K, Koseki T, Ohguchi M, Kizaki M, Ikeda Y and Nishihara T: Activin a induction of cell-cycle arrest involves modulation of cyclin D2 and p21 CIP1/WAF1 in plasmacytic cells. Mol Endocrinol 11(8): 1044-1052, 1997. PMID: 9212052. DOI: 10.1210/mend.11.8.9953
20 Joypaul BV, Hopwood D, Newman EL, Qureshi S, Grant A, Ogston SA, Lane DP and Cuschieri A: The prognostic significance of the accumulation of p53 tumour-suppressor gene protein in gastric adenocarcinoma. Br J Cancer 69(5): 943-946, 1994. PMID: 8180028. DOI: 10.1038/bjc.1994.182

21 Starzynska T, Bromley M, Ghosh A and Stern PL: Prognostic significance of p53 overexpression in gastric and colorectal carcinoma. Br J Cancer 66(3): 558-562, 1992. PMID: 1520594. DOI: $10.1038 /$ bjc. 1992.314

22 Victorzon M, Nordling S, Haglund C, Lundin J and Roberts PJ: Expression of p53 protein as a prognostic factor in patients with gastric cancer. Eur J Cancer 32A(2): 215-220, 1996. PMID: 8664030. DOI: $10.1016 / 0959-8049(95) 00547-1$

23 Finlay CA, Hinds PW, Tan TH, Eliyahu D, Oren M and Levine AJ: Activating mutations for transformation by $\mathrm{p} 53$ produce a gene product that forms an hsc70-p53 complex with an altered half-life. Mol Cell Biol 8(2): 531-539, 1988. PMID: 2832726. DOI: $10.1128 / \mathrm{mcb} .8 .2 .531$

24 Bao J, Nanding A, Song H, Xu R, Qu G and Xue Y: The overexpression of MDM4: An effective and novel predictor of gastric adenocarcinoma lymph node metastasis. Oncotarget 7(41): 67212-67222, 2016. PMID: 27626496. DOI: 10.18632/ oncotarget.11971

25 Mayo LD, Dixon JE, Durden DL, Tonks NK and Donner DB: PTEN protects p53 from Mdm2 and sensitizes cancer cells to chemotherapy. J Biol Chem 277(7): 5484-5489, 2002. PMID: 11729185. DOI: 10.1074/jbc.M108302200

26 Chang CJ, Freeman DJ and Wu H: PTEN regulates Mdm2 expression through the P1 promoter. J Biol Chem 279(28): 2984129848, 2004. PMID: 15090541. DOI: 10.1074/jbc.M401488200

27 Pan Y and Chen J: MDM2 promotes ubiquitination and degradation of MDMX. Mol Cell Biol 23(15): 5113-5121, 2003. PMID:12860999. DOI: 10.1128/mcb.23.15.5113-5121.2003

28 Kang YH, Lee HS and Kim WH: Promoter methylation and silencing of PTEN in gastric carcinoma. Lab Invest 82(3): 285-291, 2002. PMID: 11896207. DOI: 10.1038/labinvest. 3780422

29 Hirose M, Yamato K, Endo S, Saito R, Ueno T, Hirai S, Suzuki $\mathrm{H}$, Abei M, Natori Y and Hyodo I: MDM4 expression as an indicator of TP53 reactivation by combined targeting of MDM2 and MDM4 in cancer cells without TP53 mutation. Oncoscience 1(12): 830-843, 2014. PMID: 25621298. DOI: 10.18632/ oncoscience. 103

30 Kiyonari S, Iimori M, Matsuoka K, Watanabe S, MorikawaIchinose T, Miura D, Niimi S, Saeki H, Tokunaga E, Oki E, Morita M, Kadomatsu K, Maehara Y and Kitao H: The 1,2diaminocyclohexane carrier ligand in oxaliplatin induces p53dependent transcriptional repression of factors involved in thymidylate biosynthesis. Mol Cancer Ther 14(10): 2332-2342, 2015. PMID: 26208523. DOI: 10.1158/1535-7163.MCT-14-0748

31 Boyer J, McLean EG, Aroori S, Wilson P, McCulla A, Carey PD, Longley DB and Johnston PG: Characterization of p53 wild-type and null isogenic colorectal cancer cell lines resistant to 5fluorouracil, oxaliplatin, and irinotecan. Clin Cancer Res 10(6): 2158-2167, 2004. PMID: 15041737. DOI: 10.1158/1078-0432.ccr03-0362

Received December 27, 2020

Revised January 14, 2021

Accepted January 21, 2021 